\title{
Un dibujo de Ana de Austria por Crispin van der Broeck
}

\author{
Julia de la Torre Fazio \\ Universidad de Málaga
}

Cuando el 3 de octubre de 1568 muere Isabel de Valois, Felipe II queda viudo por tercera vez y sin heredero varón. Una nueva boda era, pues, obligada. La elegida en esta ocasión fue la archiduquesa Ana de Austria, sobrina de Felipe II, hija de su hermana María y de Maximiliano II, emperador de Austria. Se imponía de nuevo la razón de Estado en el matrimonio del monarca, ya que la amistad con los Habsburgo aseguraba su apoyo en la política española de Europa central y dejaba el camino libre hacia las posesiones italianas y flamencas. Las capitulaciones matrimoniales se firmaron en Madrid el 24 de enero de 1570 y en mayo se celebró, en el castillo de Praga, la boda por poderes.

Las maniobras turcas en el Mediterráneo obligaron a un cambio en el itinerario previsto, con lo que, en vez de en Génova, la entrega de la novia se produjo en los Países Bajos. La familia imperial había acompañado a la joven reina desde Praga hasta Spira, donde se separaron el 18 de julio. Ana, junto con sus hermanos Wenceslao y Alberto, que iban a educarse en la corte española, se dirigieron a través del Rhin hacia territorio flamenco. A su llegada a Nimega, el 15 de agosto de 1570, les esperaba el duque de Alba, gobernador de los Países Bajos, que había organizado un gran recibimiento para la nueva reina. Las fiestas, de las que se conserva una única relación, duraron cuatro días durante los cuales se realizó la entrega oficial de la reina al duque de Alba1. Concluido el recibimiento, la comitiva real se dirige, a través de Grave, Bois le Duc y Breda, a Bergen-op-Zoon, donde llegaron el 21 de agosto. El 25 de septiembre, con un considerable retraso debido al mal tiempo, embarcan hacia España.

Es este el momento que el pintor flamenco Crispin van den Broeck plasmó en su dibujo conservado en la Albertina de Viena. Según indica Karel van Mander, van der Broeck (c. 1524-c.1591) fue un arquitecto, pintor y grabador seguidor de Frans Flooris $^{2}$. Tras recibir enseñanzas de su padre, también artista, entró en 1555 en el gremio de pintores de Amberes $^{3}$. Se conservan algunas obras suyas entre las que destaca el lienzo representado a Dos hombres jóvenes (c.1590, Fitzwilliam Museum), así

* TORRE FAZIO, Julia: “Un dibujo de Ana de Austria por Crispin van der Broecken”, en Boletín de Arte, n 29 Departamento de Historia del Arte, Universidad de Málaga, 2008, págs. 551-561.

1 SANZ, Ma Jesús, "Festivas demostraciones de Nimega y Burgos en honor de la reina doña Ana de Austria" en Boletín del Seminario de Estudios de Arte y Arqueología, XLIX, Universidad de Valladolid, 1983.

$2 \mathrm{http}: / /$ getty.edu/vow/ULANFullDisplay?find=\&role=\&nation=\&subjectid=500029763

3 MÜLLER, Hermann Alexander y SINGER, Hans Wolfgang, Allgemeines Künstler-Lexicon. Leben und Werke der berühmtesten Bildenden Küstler, I. Band, Rütten \& Loening, Frankfurt A/M, 1895.

4 BRYAN, Michael, A biographical dictionary of painters and engravers, London, 1865. 


Q. varia Julia de la Torre Fazio

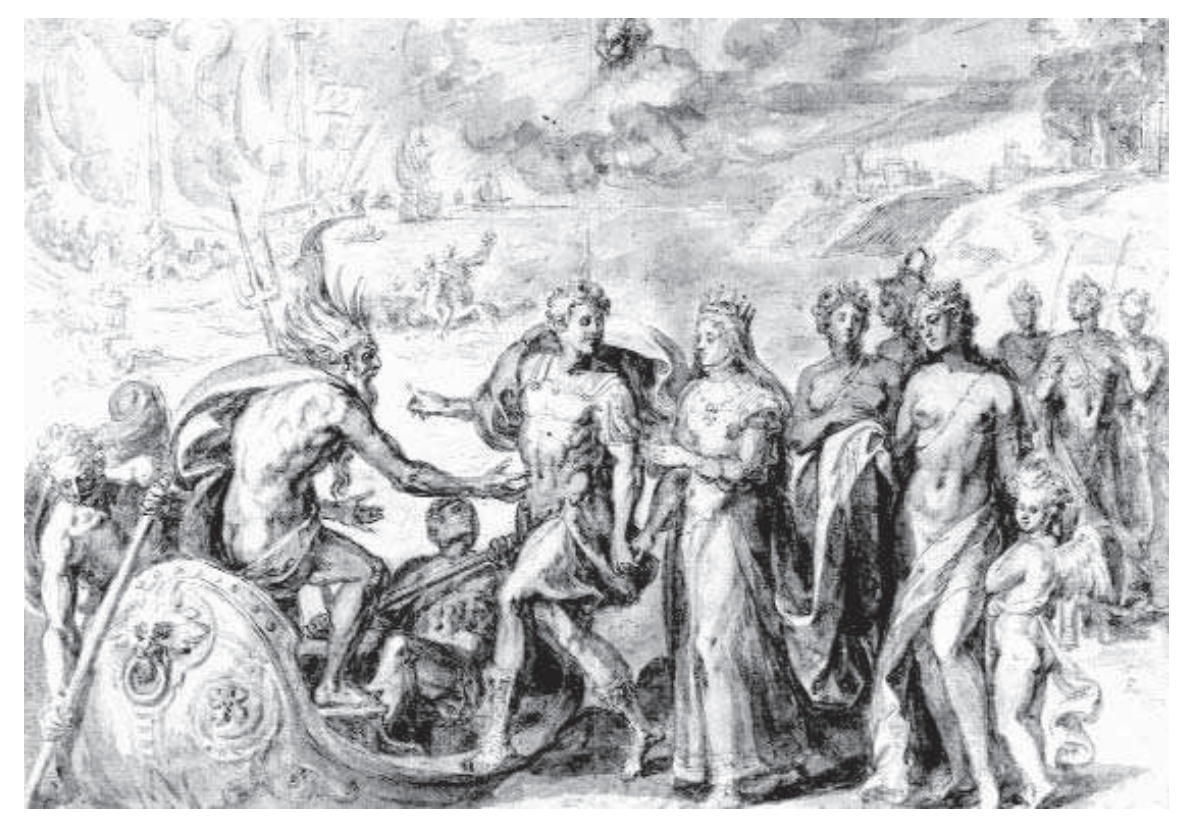

1. CRISPIN VAN DER BROEC. Ana de Austria.

como varias series de grabados en madera de tema religioso 4 . Se conocen algunos otros dibujos en tinta -Courtauld Institute of Art Gallery de Londres y Museos de Bellas Artes de Rennes y Bruselas, entre otros- caracterizados, al igual que el que se presenta, por la delicadeza de sus trazos y la maestría en la composición de la escena.

El dibujo en cuestión, hasta ahora inédito en los estudios españoles sobre Ana de Austria, es una alegoría mitológica de la situación que rodea el embarque. En 1570 los Países Bajos vivían el momento de mayor tensión política. El duque de Alba había sido nombrado gobernador por Felipe II y había emprendido una serie de medidas destinadas a aplastar la oposición política y religiosa que derivó en numerosas revueltas y motines que ponían en peligro el viaje de la nueva reina ${ }^{5}$. La reina, que había tenido que retrasar varios días su embarque debe ser protegida por el mismo Neptuno, que la salvará de las dos grandes adversidades que debía sortear en su viaje hacia España: el mal tiempo, representado por uno de los dioses del viento -en la parte superior le vemos generando un gran vendaval- y los barcos enemigos -en segundo plano, en el lado izquierdo-. Junto a la reina aparece una comitiva de dio-

5 LYNCH, John, Los Austrias 1516-1700, Crítica, Barcelona, 2003. 


\section{Varia Un dibujo de Ana de Austria por Crispin van der Broeck}

ses mitológicos entre los que se puede apreciar a Marte, ataviado como un militar romano, en el momento de entregar a doña Ana en las manos de Neptuno. Tras ellos aparecen Atenea, Diana y Venus, junto a Cupido ${ }^{6}$.

El interés de este dibujo radica en que representa, alegóricamente, el inicio del largo viaje de la ya reina de España Ana de Austria a Madrid. Un viaje marcado por la fastuosidad y complejidad iconográfica de los diferentes recibimientos triunfales celebrados, en primer lugar, tras desembarcar en Laredo, en Burgos ${ }^{7}$; posteriormente, en Segovia, donde celebraría también sus esponsales 8 ; y, por último, en Madrid, nueva capital del reino y escenario de la entrada definitiva de la reina en la Corte española9.

6 GONZÁLEZ DE ZÁRATE, Jesús María, Mitología e historia del arte, Instituto Ephialte, Vitoria, 1997.

7 SANZ, Ma Jesús, op. Cit.

8 FERNÁNDEZ DE HERRERA, Juan, Relación verdadera del recibimiento que hizo la ciudad de Segovia a Nuestra Señora Doña Ana de Austria en su felicísimo casamiento que en la dicha ciudad se celebró, Alcalá de Henares, 1572.

9 LÓPEZ DE HOYOS, Juan, Real Aparato y Sumptuoso Recebimiento con que Madrid recibió a la Serenísima Reina Doña Ana de Austria..., Madrid, 1582, publicada por SIMÓN DÍAZ, J., Fuentes para la Historia de Madrid y su provincia, tomo I, Madrid, 1964, págs. 55.118. 